\title{
A MAIA TYPE FIXED POINT THEOREM FOR PREŠIĆ-KANNAN OPERATORS
}

\author{
MARGARETA-ELIZA BALAZS
}

Received 16 November, 2015

\begin{abstract}
Starting from Prešić's fixed point theorem, established in [Prešić, Slaviša B. Sur une classe d'inéquations aux différences finies et sur la convergence de certaines suites. (French) Publ. Inst. Math. (Beograd) (N.S.) 5 (19) 1965 75-78] on the one hand, and Maia's fixed point theorem obtained in [Maia, Maria Grazia. Un'osservazione sulle contrazioni metriche. (Italian) Rend. Sem. Mat. Univ. Padova 401968 139-143] on the other hand, two different extensions of Banach fixed point theorem are extended, generalised and unified.
\end{abstract}

2010 Mathematics Subject Classification: 47H10; 54H25

Keywords: fixed point, metric space, Presic-Kannan operator, extension of Banach fixed point theorem

\section{INTRODUCTION AND PRELIMINARIES}

In 1965, S. Prešić [4] extended the famous Banach contraction principle [1] to the case of product spaces and obtained convergence results for some particular sequences. Prešić type operators have applications in solving nonlinear difference equations, cyclic systems and in the study of convergence of sequences. Prešić's result may be stated as follows:

Theorem 1 ([5]). Let $(X, d)$ be a complete metric space, $k$ a positve integer and $f: X^{k} \rightarrow X$ a Prešić operator, it is, a mapping for which there exists $\alpha_{1}, \alpha_{2}, \ldots, \alpha_{k} \in$ $\mathbb{R}_{+}, \sum_{i=1}^{k} \alpha_{i}=\alpha<1$ such that:

$$
d\left(f\left(x_{0}, \ldots, x_{k-1}\right), f\left(x_{1}, \ldots, x_{k}\right)\right) \leq \sum_{i=1}^{k} \alpha_{i} d\left(x_{i-1}, x_{i}\right),
$$

for all $x_{0}, \ldots, x_{k} \in X$.

Then:

1) $f$ has a unique fixed point $x^{*}$;

2) the sequence $\left\{y_{n}\right\}_{n \geq 0}$, 


$$
y_{n+1}=f\left(y_{n}, y_{n}, \ldots, y_{n}\right), n \geq 0,
$$

converges to $x^{*}$;

3) the sequence $\left\{x_{n}\right\}_{n \geq 0}$ with $x_{0}, \ldots, x_{k-1} \in X$ and

$$
x_{n}=f\left(x_{n-k}, x_{n-k+1}, \ldots, x_{n-1}\right), n \geq k,
$$

also converges to $x^{*}$, with a rate estimated by

$$
d\left(x_{n+1}, x^{*}\right) \leq \alpha d\left(x_{n}, x^{*}\right)+M \cdot \theta^{n}, n \geq 0,
$$

where $M>0$ is constant.

The following result was given by M. G. Maia in 1968 and is also a generalization of Banach contraction mapping principle for sets endowed with two comparable metrics.

Theorem 2 ([8], [3]). Let $X$ be a nonempty set, $d$ and $\rho$ two metrics on $X$ and $f: X \rightarrow X$ an operator. We suppose that:

(i) $d(x, y) \leq \rho(x, y)$ for all $x, y \in X$;

(ii) $(X, d)$ is a complete metric space;

(iii) $f:(X, d) \rightarrow(X, d)$ is continuous;

(iv) $f:(X, \rho) \rightarrow(X, \rho)$ is an $\alpha$-contraction.

Then:
(a) $F_{f}=\left\{x^{*}\right\}$;
(b) $f^{n}(x) \stackrel{d}{\rightarrow} x^{*}$ as $n \rightarrow \infty$, for all $x \in X$;
(c) $f^{n}(x) \stackrel{\rho}{\rightarrow} x^{*}$ as $n \rightarrow \infty$, for all $x \in X$;
(d) $\rho\left(x, x^{*}\right) \leq \frac{1}{1-\alpha} \rho(x, f(x))$, for each $x \in X$.

Remark 1. Particular cases:

1. From Maia's fixed point theorem when $d \equiv \rho$, we get Banach's fixed point theorem.

2. From Prešić's fixed point theorem when $k=1$, we get Banach's fixed point theorem.

3. A Prešić-Maia type fixed point theorem has been obtained by Shukla, S. and Radenović, S. in [9].

Prešić's fixed point theorem has been extended by Păcurar to the case when the Banach type contraction condition (1.1) is replaced by a Prešić-Kannan type contraction.

Theorem 3 ([5],[2]). Let $(X, d)$ be a complete metric space, $k$ a positive integer, $a \in \mathbb{R}$ a constant such that $0 \leq a \cdot k \cdot(k+1)<1$ and $f: X^{k} \rightarrow X$ an operator satisfying the following condition: 


$$
\begin{gathered}
d\left(f\left(x_{0}, x_{1}, \ldots, x_{k-1}\right), f\left(x_{1}, x_{2}, \ldots, x_{k}\right)\right) \leq \\
\leq a \cdot d\left(x_{0}, f\left(x_{0}, \ldots, x_{0}\right)\right)+a \cdot d\left(x_{1}, f\left(x_{1}, \ldots, x_{1}\right)\right)+\cdots+ \\
+a \cdot d\left(x_{k}, f\left(x_{k}, \ldots, x_{k}\right)\right),
\end{gathered}
$$

for any $x_{0}, x_{1}, \ldots, x_{k} \in X$.

Then:

1) $f$ has a unique fixed point $x^{*}$;

2) the sequence $\left\{y_{n}\right\}_{n \geq 0}$,

$$
y_{n+1}=f\left(y_{n}, y_{n}, \ldots, y_{n}\right), n \geq 0,
$$

converges to $x^{*}$;

3) the sequence $\left\{x_{n}\right\}_{n \geq 0}$ with $x_{0}, \ldots, x_{k-1} \in X$ and

$$
x_{n}=f\left(x_{n-k}, x_{n-k+1}, \ldots, x_{n-1}\right), n \geq k,
$$

also converges to $x^{*}$, with a rate estimated by

$$
d\left(x_{n+1}, x^{*}\right) \leq C \cdot \theta^{n}, n \geq 0,
$$

where $C$ is a positive constant.

Starting from these results, the aim of this paper is to extend Theorem 3 to the case of a set endowed with two comparable metrics.

We shall need in our proof the following lemma given by S. Prešić in [4].

Lemma 1. Let $k \in \mathbb{N}, k \neq 0$ and $\alpha_{1}, \alpha_{2}, \ldots, \alpha_{k} \in \mathbb{R}_{+}$such that $\sum_{i=1}^{k} \alpha_{i}=\alpha<1$. If $\left\{\Delta_{n}\right\}_{n \geq 1}$ is a sequence of positive numbers satisfying

$$
\Delta_{n+k} \leq \alpha_{1} \Delta_{n}+\alpha_{2} \Delta_{n+1}+\cdots+\alpha_{k} \Delta_{n+k-1}, n \geq 1,
$$

then there exist $L>0$ and $\theta \in(0,1)$ such that

$$
\Delta_{n} \leq L \cdot \theta^{n} \text {, for all } n \geq 1 \text {. }
$$

Remark 2. The following consideration shall simplify our approach in this proof [7].

For any operator $f: X^{k} \rightarrow X, k$ a positive integer, we can define its associate operator $F: X \rightarrow X$ by

$$
F(x)=f(x, \ldots, x), x \in X .
$$

Obviously, $x \in X$ is a fixed point of $f: X^{k} \rightarrow X$ if and only if it is a fixed point of its associate operator $F$. This enables the study of $f$ by means of the operator $F$. 


\section{THE MAIN RESULT}

Theorem 4 (Maia fixed point theorem for Prešić-Kannan operators). Let $X$ be a nonempty set, $d$ and $\rho$ two metrics on $X$ and $k$ a positive integer, $a \in \mathbb{R}$ a constant such that $0 \leq a \cdot k \cdot(k+1)<1$ and $f: X^{k} \rightarrow X$ an operator satisfying the following condition:

$$
\begin{gathered}
\rho\left(f\left(x_{0}, x_{1}, \ldots, x_{k-1}\right), f\left(x_{1}, x_{2}, \ldots, x_{k}\right)\right) \leq \\
\leq a \cdot \rho\left(x_{0}, f\left(x_{0}, \ldots, x_{0}\right)\right)+a \cdot \rho\left(x_{1}, f\left(x_{1}, \ldots, x_{1}\right)\right)+ \\
+\cdots+a \cdot \rho\left(x_{k}, f\left(x_{k}, \ldots, x_{k}\right)\right)
\end{gathered}
$$

for any $x_{0}, x_{1}, \ldots, x_{k} \in X$.

We suppose that:

(i) $d(x, y) \leq \rho(x, y)$ for all $x, y \in X$;

(ii) $(X, d)$ is a complete metric space;

(i i i ) $f:\left(X^{k}, d\right) \rightarrow(X, d)$ is continuous;

Then:

(a) $f$ has a unique fixed point $x^{*}, F_{f}=x^{*}, f\left(x^{*}, x^{*}, \ldots, x^{*}\right)=x^{*}$;

(b) the sequence $\left\{x_{n}\right\}_{n \geq 0}$ with $x_{0}, \ldots, x_{k-1} \in X$ and

$$
x_{n+1}=f\left(x_{n}, x_{n-1}, \ldots, x_{n-k+1}\right), n \geq k-1,
$$

converges to $x^{*}$ with respect to $d$;

(c) the sequence $\left\{y_{n}\right\}_{n \geq 0}$,

$$
y_{n+1}=f\left(y_{n}, y_{n}, \ldots, y_{n}\right), n \geq 0,
$$

converges to $x^{*}$ with respect to $\rho$;

(d) the following estimate holds

$$
\rho\left(x_{n+1}, x^{*}\right) \leq C \cdot \theta^{n}, n \geq 0,
$$

where $C$ is a positive constant.

Proof. (c): From $\left\{y_{n}\right\}_{n \geq 0}, y_{n+1}=f\left(y_{n}, y_{n}, \ldots, y_{n}\right), n \geq 0$ and considering the associate operator $F: X \rightarrow X, F(x)=f(x, x, \ldots, x)$, for any $x, y \in X$ we have:

$$
\begin{gathered}
\rho(F(x), F(y)))=\rho(f(x, x, \ldots, x), f(y, y, \ldots, y)) \leq \\
\leq \rho(f(x, x, \ldots, x), f(x, x, \ldots, y))+ \\
+\rho(f(x, x, \ldots, y), f(x, \ldots, x, y, y))+ \\
+\cdots+ \\
+\rho(f(x, y, \ldots, y), f(y, y, \ldots, y)) .
\end{gathered}
$$

By condition (1.2) and inequality (2.5) it follows

$$
\rho(F(x), F(y))) \leq a \cdot \frac{k \cdot(k+1)}{2} \cdot[\rho(x, F(x))+\rho(y, F(y))]
$$


for any $x, y \in X$. As $a$ was assumed to satisfy $0 \leq a \cdot k \cdot(k+1)<1$, it follows that

$$
0 \leq a \cdot \frac{k \cdot(k+1)}{2}<\frac{1}{2}
$$

so $F$ is a Kannan operator.

According to Kannan's theorem [2], there exists a unique $x^{*} \in X$ such that $F\left(x^{*}\right)=x^{*}$, namely that $x^{*}=f\left(x^{*}, x^{*}, \ldots, x^{*}\right)$ and this can be obtained as limit of the sequence of successive approximations of $F$, which is exactly the sequence $\left\{y_{n}\right\}_{n \geq 0}$, defined by $y_{n+1}=f\left(y_{n}, y_{n}, \ldots, y_{n}\right), n \geq 0$, so

$$
\lim _{n \rightarrow \infty} F\left(y_{n}\right)=x^{*}, F\left(y_{n}\right) \text { converges to } x^{*}=f\left(x^{*}, x^{*}, \ldots, x^{*}\right) \text { in }(X, \rho)
$$

and

$$
y_{n+1}=f\left(y_{n}, y_{n}, \ldots, y_{n}\right) \text { converges to } x^{*}=f\left(x^{*}, x^{*}, \ldots, x^{*}\right) .
$$

$(a),(b)$ : Let $\left\{x_{n}\right\}_{n \geq 0}, x_{n+1}=f\left(x_{n}, x_{n-1}, \ldots, x_{n-k+1}\right), n \geq k-1$.

For $n \geq 0$ we have:

$$
\begin{gathered}
\rho\left(x_{n+1}, x^{*}\right)=\rho\left(f\left(x_{n}, x_{n-1}, \ldots, x_{n-k+1}\right), f\left(x^{*}, x^{*}, \ldots, x^{*}\right)\right) \leq \\
\leq \rho\left(f\left(x_{n}, x_{n-1}, \ldots, x_{n-k+1}\right), f\left(x_{n-1}, \ldots, x_{n-k+1}, x^{*}\right)\right)+ \\
+\rho\left(f\left(x_{n-1}, \ldots, x_{n-k+1}, x^{*}\right), f\left(x_{n-2}, \ldots, x_{n-k+1}, x^{*}, x^{*}\right)\right)+ \\
+\cdots+ \\
+\rho\left(f\left(x_{n-k+1}, x^{*}, \ldots, x^{*}\right), f\left(x^{*}, x^{*}, \ldots, x^{*}\right)\right) .
\end{gathered}
$$

Let $F: X \rightarrow X, F(x)=f(x, x, \ldots, x), x \in X$ and using the condition (1.2) in the inequality above, we get:

$$
\begin{gathered}
\rho\left(x_{n+1}, x^{*}\right) \leq a \cdot\left[\rho\left(x_{n}, F\left(x_{n}\right)\right)+\cdots+\right. \\
\left.+\rho\left(x_{n-k+1}, F\left(x_{n-k+1}\right)\right)+\rho\left(x^{*}, F\left(x^{*}\right)\right)\right]+ \\
+a \cdot\left[\rho\left(x_{n-1}, F\left(x_{n-1}\right)\right)+\cdots+\rho\left(x_{n-k+1}, F\left(x_{n-k+1}\right)\right)+\right. \\
\left.+\rho\left(x^{*}, F\left(x^{*}\right)\right)+\rho\left(x^{*}, F\left(x^{*}\right)\right)\right]+ \\
+\cdots+ \\
+a \cdot\left[\rho\left(x_{n-k+1}, F\left(x_{n-k+1}\right)\right)+\rho\left(x^{*}, F\left(x^{*}\right)\right)+\cdots+\rho\left(x^{*}, F\left(x^{*}\right)\right)\right] .
\end{gathered}
$$

Since $\rho\left(x^{*}, F\left(x^{*}\right)\right)=0$, this implies:

$$
\begin{gathered}
\rho\left(x_{n+1}, x^{*}\right) \leq a \cdot\left[1 \cdot \rho\left(x_{n}, F\left(x_{n}\right)\right)+2 \cdot \rho\left(x_{n-1}, F\left(x_{n-1}\right)\right)+\right. \\
\left.\cdots+k \cdot \rho\left(x_{n-k+1}, F\left(x_{n-k+1}\right)\right)\right]
\end{gathered}
$$

For each $j \in \mathbb{N}$ the following holds:

$$
\rho\left(x_{j}, F\left(x_{j}\right)\right) \leq \rho\left(x_{j}, x^{*}\right)+\rho\left(x^{*}, F\left(x_{j}\right)\right)
$$

and $\rho\left(x^{*}, F\left(x_{j}\right)\right)=\rho\left(F\left(x^{*}\right), F\left(x_{j}\right)\right)$

$$
\rho\left(F\left(x^{*}\right), F\left(x_{j}\right)\right) \leq
$$




$$
\begin{aligned}
& a \cdot {[\underbrace{\rho\left(x^{*}, f\left(x^{*}, x^{*}, \ldots, x^{*}\right)\right)+\cdots+\rho\left(x^{*}, f\left(x^{*}, x^{*}, \ldots, x^{*}\right)\right)}_{k \text { times }}+} \\
&\left.+\rho\left(x_{j}, f\left(x_{j}, x_{j}, \ldots, x_{j}\right)\right)\right]+ \\
&+a \cdot[\underbrace{\rho\left(x^{*}, f\left(x^{*}, x^{*}, \ldots, x^{*}\right)\right)+\cdots+\rho\left(x^{*}, f\left(x^{*}, x^{*}, \ldots, x^{*}\right)\right)}_{k-1 \text { times }}+ \\
&+\underbrace{\rho\left(x_{j}, f\left(x_{j}, x_{j}, \ldots, x_{j}\right)\right)+\rho\left(x_{j}, f\left(x_{j}, x_{j}, \ldots, x_{j}\right)\right)}_{2 \text { times }}]+ \\
&+\underbrace{\rho\left(x_{j}, f\left(x_{j}, x_{j}, \ldots, x_{j}\right)\right)+\cdots+\rho\left(x_{j}, f\left(x_{j}, x_{j}, \ldots, x_{j}\right)\right)}_{k \text { times }}]
\end{aligned}
$$

so

$$
\begin{gathered}
\rho\left(F\left(x^{*}\right), F\left(x_{j}\right)\right) \leq a \cdot \rho\left(x^{*}, f\left(x^{*}, x^{*}, \ldots, x^{*}\right)\right) \cdot[k+(k-1)+\cdots+1]+ \\
+a \cdot \rho\left(x_{j}, f\left(x_{j}, x_{j}, \ldots, x_{j}\right)\right) \cdot[1+2+\cdots+k]
\end{gathered}
$$

and finally

$$
\begin{gathered}
\rho\left(F\left(x^{*}\right), F\left(x_{j}\right)\right) \leq a \cdot \frac{k \cdot(k+1)}{2} \cdot\left[\rho\left(x^{*}, f\left(x^{*}, x^{*}, \ldots, x^{*}\right)\right)+\right. \\
\left.\rho\left(x_{j}, f\left(x_{j}, x_{j}, \ldots, x_{j}\right)\right)\right] .
\end{gathered}
$$

Thus

$$
\rho\left(F\left(x^{*}\right), F\left(x_{j}\right)\right) \leq a \cdot \frac{k \cdot(k+1)}{2} \cdot\left[\rho\left(x^{*}, F\left(x^{*}\right)\right)+\rho\left(x_{j}, F\left(x_{j}\right)\right)\right]
$$

and

Thus (2.5) becomes:

$$
\begin{gathered}
\rho\left(x^{*}, F\left(x_{j}\right)\right)=\rho\left(F\left(x^{*}\right), F\left(x_{j}\right)\right) \leq \\
\leq a \cdot \frac{k \cdot(k+1)}{2} \cdot\left[\rho\left(x^{*}, F\left(x^{*}\right)\right)+\rho\left(x_{j}, F\left(x_{j}\right)\right)\right]= \\
=a \cdot \frac{k \cdot(k+1)}{2} \cdot \rho\left(x_{j}, F\left(x_{j}\right)\right) .
\end{gathered}
$$

$$
\rho\left(x_{j}, F\left(x_{j}\right)\right) \leq \rho\left(x_{j}, x^{*}\right)+a \cdot \frac{k \cdot(k+1)}{2} \cdot \rho\left(x_{j}, F\left(x_{j}\right)\right) .
$$

By denoting $A=a \cdot \frac{k \cdot(k+1)}{2}$ we have

$$
\rho\left(x_{j}, F\left(x_{j}\right)\right) \leq \frac{1}{1-A} \cdot \rho\left(x_{j}, x^{*}\right)
$$

Using (2.6) in inequality (2.3) we obtain

$$
\rho\left(x_{n+1}, x^{*}\right) \leq
$$




$$
\leq \frac{a}{1-A} \cdot \rho\left(x_{n}, x^{*}\right)+\frac{2 \cdot a}{1-A} \cdot \rho\left(x_{n-1}, x^{*}\right)+\cdots+\frac{k \cdot a}{1-A} \cdot \rho\left(x_{n-k+1}, x^{*}\right)
$$

Now by denoting

the inequality (2) becomes

$$
\begin{aligned}
& \Delta_{n}=\rho\left(x_{n}, x^{*}\right), n \geq 0 \\
& \alpha_{i}=\frac{i \cdot a}{1-A}, i=\overline{1, k},
\end{aligned}
$$

$$
\Delta_{n+1} \leq \alpha_{1} \cdot \Delta_{n}+\alpha_{2} \cdot \Delta_{n-1}+\cdots+\alpha_{k} \cdot \Delta_{n-k+1}, n \geq k .
$$

The coefficients $\alpha_{1}, \alpha_{2}, \ldots, \alpha_{k}$ are all positive, as $0<a<\frac{1}{k \cdot(k+1)}$.

Besides

$$
\sum_{i=1}^{k} \alpha_{i}=\sum_{i=1}^{k} \frac{i \cdot a}{1-A}=\frac{a}{1-A} \cdot \sum_{i=1}^{k} i=\frac{a}{1-A} \cdot \frac{k \cdot(k+1)}{2}=\frac{A}{1-A} .
$$

So from

we have

$$
\begin{gathered}
0<a \cdot k \cdot(k+1)<1 \\
0<\frac{a \cdot k \cdot(k+1)}{2}<\frac{1}{2} \\
0<A<\frac{1}{2}<1
\end{gathered}
$$

$$
\sum_{i=1}^{k} \alpha_{i}=\frac{A}{1-A}<1
$$

Now the conditions required in Lemma (1.1) are fulfilled. Consequently there exist $L \geq 0$ and $\theta \in(0,1)$ such that $\Delta_{n} \leq L \cdot \theta^{n}, n \geq 1$, namely such that

$$
\rho\left(x_{n}, x^{*}\right) \leq L \cdot \theta^{n}, n \geq 1 \text {. }
$$

Using (2.9) in the inequality (2) we have:

$$
\begin{gathered}
\rho\left(x_{n+1}, x^{*}\right) \leq \\
\leq \frac{a}{1-A} \cdot L \cdot \theta^{n}+\frac{2 \cdot a}{1-A} \cdot L \cdot \theta^{n-1}+\cdots+\frac{k \cdot a}{1-A} \cdot L \cdot \theta^{n-k+1} \leq \\
\leq \theta^{n} \cdot \frac{a \cdot L}{1-A} \cdot\left(1+2 \cdot \theta^{-1}+\cdots+k \cdot \theta^{1-k}\right)= \\
=\theta^{n} \cdot \frac{a \cdot L}{1-A} \cdot \sum_{i=1}^{k} i \cdot \theta^{1-i}, L \geq 0, \theta>0 .
\end{gathered}
$$

This inequality shall lead to estimate $(d)$, where:

$$
C=\frac{a \cdot L}{1-A} \cdot \sum_{i=1}^{k} i \cdot \theta^{1-i}>0
$$




$$
\rho\left(x_{n+1}, x^{*}\right) \leq C \cdot \theta^{n}, n \geq 0 .
$$

It follows immediately that $\rho\left(x_{n+1}, x^{*}\right) \rightarrow 0$ as $n \rightarrow \infty$, so the sequence $\left\{x_{n}\right\}_{n \geq 0}$ converges to $x^{*}$ in $(X, \rho)$, and $x^{*}$ is the unique fixed point of the operator $f$.

For $n \geq 0$, from (i) and (2.10) we obtain

$$
d\left(x_{n+1}, x^{*}\right) \leq \rho\left(x_{n+1}, x^{*}\right)<\varepsilon .
$$

Since $\theta \in(0,1)$, it follows that $\left\{x_{n}\right\}_{n \geq 0}$ is a Cauchy sequence in $(X, d)$, which in the complete metric space $(X, d)$ is also convergent.

From the continuity of $f$ in $(X, d)$,

$$
\lim _{n \rightarrow \infty} d\left(f\left(x_{n}, x_{n-1}, \ldots, x_{n-k+1}\right), f\left(x^{*}, x^{*}, \ldots, x^{*}\right)\right)=0
$$

we get

$$
\lim _{n \rightarrow \infty} f\left(x_{n}, x_{n-1}, \ldots, x_{n-k+1}\right)=f\left(x^{*}, x^{*}, \ldots, x^{*}\right) \text { in }(X, d)
$$

and $\left\{x_{n}\right\}_{n \geq 0}$ converges to $x^{*}$ in $(X, d)$ and $F_{f}=x^{*}, x^{*}=f\left(x^{*}, x^{*}, \ldots, x^{*}\right)$.

Remark 3. We have the following important particular cases of Theorem 4:

1. If $k=1$, by Theorem 4 we get a Maia fixed point theorem corresponding to Kannan contraction condition. Kannan fixed point theorem is obtained in the particular case when $d=\rho$. Note that the original Maia's fixed point theorem is established for the case of Banach's contraction condition.

2. If $d=\rho$, by Theorem 4 we get Păcurar's fixed point theorem [6].

Example 1. Let $X=[0,1]$ endowed with two metrics $d$ and $\rho$. For $k=2$ define $f: X^{2} \rightarrow X$ by

$$
f(x, y)=\left\{\begin{array}{r}
\frac{x+y}{6},(x, y) \in[0,1], x \geq y, \\
0, \text { otherwise } .
\end{array}\right.
$$

Then $f$ is a Prešić-Kannan contraction.

Proof. In the first part of the proof we will show that $f$ is a Prešić-Kannan operator. In this particular case condition (2.1) becomes:

$$
\begin{gathered}
\rho\left(f\left(x_{0}, x_{1}\right), f\left(x_{1}, x_{2}\right)\right) \leq a \cdot \rho\left(x_{0}, f\left(x_{0}, x_{0}\right)\right)+ \\
+a \cdot \rho\left(x_{1}, f\left(x_{1}, x_{1}\right)\right)+a \cdot \rho\left(x_{2}, f\left(x_{2}, x_{2}\right)\right),
\end{gathered}
$$

with $x_{0}>x_{1}>x_{2}$.

If $k=2$ then $0 \leq a<\frac{1}{6}$.

For $x_{0}=1, x_{1}=x_{2}=0$

$$
\rho\left(f\left(x_{0}, x_{1}\right), f\left(x_{1}, x_{2}\right)\right)=\rho(f(1,0), f(0,0))=\rho\left(\frac{1}{6}, 0\right)=\frac{1}{36} \leq
$$


so

$$
\begin{gathered}
\leq a \cdot \rho(1, f(1,1))+a \cdot \rho(0, f(0,0))+a \cdot \rho(0, f(0,0))= \\
=a \cdot\left[\rho\left(1, \frac{1}{3}\right)+0+0\right]=a \cdot \frac{2}{9}
\end{gathered}
$$

it follows that

$$
\frac{1}{36} \leq a \cdot \frac{2}{9}
$$

$$
a \geq \frac{1}{8}
$$

The conclusion is that $f$ given by (2.11) is a Prešić-Kannan operator, that is, it satisfies (2.1) for any $x_{0}, x_{1}, x_{2} \in[0,1], x_{0}>x_{1}>x_{2}$, with constant $a \in\left[\frac{1}{8}, \frac{1}{6}\right)$.

Let $\left\{x_{n}\right\}_{n \geq 0}, x_{n+2}=\left\{x_{n+1}, x_{n}\right\}, n \geq 0$. For any $x, y \in X$ we have:

$$
\rho\left(x_{n+2}, x^{*}\right) \leq C \cdot \theta^{n}, n \geq 0,
$$

where

$$
C=\frac{a \cdot L}{1-3 \cdot a} \cdot\left(1+2 \cdot \frac{1}{\theta}\right)>0 .
$$

It follows immediately that $\rho\left(x_{n+2}, x^{*}\right) \rightarrow 0$ when $n \rightarrow \infty$, so the sequence $\left\{x_{n}\right\}_{n \geq 0}$ converges to $x^{*}$ in $(X, \rho)$, and $x *=f\left(x^{*}, x^{*}\right)$ is the unique fixed point of the operator $f$.

$$
d\left(x_{n+2}, x^{*}\right) \leq \rho\left(x_{n+2}, x^{*}\right)<\epsilon
$$

Since $\theta \in(0,1)$, it follows that $\left\{x_{n}\right\}_{n \geq 0}$ is a Cauchy sequence in $(X, d)$, which in the complete metric space $(X, d)$ is also convergent.

From the continuity of $f$ in $(X, d)$,

$$
\lim _{n \rightarrow \infty} d\left(f\left(x_{n+1}, x_{n}\right), f\left(x^{*}, x^{*}\right)\right)=0
$$

we get

$$
\lim _{n \rightarrow \infty} f\left(x_{n+1}, x_{n}\right)=f\left(x^{*}, x^{*}\right) \text { in }(X, d)
$$

and $\left\{x_{n}\right\}_{n \geq 0}$ converges to $x^{*}$ in $(X, d)$ and $F_{f}=x^{*}, x^{*}=f\left(x^{*}, x^{*}\right)$.

From $\left\{\bar{y}_{n}\right\}_{n \geq 0}, y_{n+2}=f\left(y_{n}, y_{n}\right), n \geq 0$ and considering the associate operator $F: X \rightarrow X, F(x)=f(x, x)$, for any $x, y \in X$ we have:

$$
\rho(F(x), F(y))) \leq 3 \cdot a \cdot[\rho(x, F(x))+\rho(y, F(y))]
$$

for any $x, y \in X$. As $a$ was assumed to satisfy $0 \leq a \cdot k \cdot(k+1)<1$, it follows that

$$
0 \leq 3 \cdot a<\frac{1}{2}
$$

so $F$ is a Kannan operator and due to Kannan's theorem, there exist a unique fixed point $x^{*} \in X$ such that $F\left(x^{*}\right)=x^{*}$, so $\left\{y_{n}\right\}_{n \geq 0}$ converges to $x^{*}=f\left(x^{*}, x^{*}\right)$. 
The following theorem is an extension of Theorem 4 to the case of metric spaces endowed with a partial order.

Theorem 5. Let $X$ be a nonempty set equipped with partial order $\preceq, d$ and $\rho$ two metrics on $X$ and $k$ a positive integer, $a \in \mathbb{R}$ a constant such that $0 \leq a \cdot k \cdot(k+1)<1$ and $f: X^{k} \rightarrow X$ an operator satisfying the following condition:

$$
\begin{gathered}
\rho\left(f\left(x_{0}, x_{1}, \ldots, x_{k-1}\right), f\left(x_{1}, x_{2}, \ldots, x_{k}\right)\right) \leq \\
\leq a \cdot \rho\left(x_{0}, f\left(x_{0}, \ldots, x_{0}\right)\right)+a \cdot \rho\left(x_{1}, f\left(x_{1}, \ldots, x_{1}\right)\right)+ \\
+\cdots+a \cdot \rho\left(x_{k}, f\left(x_{k}, \ldots, x_{k}\right)\right),
\end{gathered}
$$

for any $x_{0}, x_{1}, \ldots, x_{k} \in X$ with $x_{0} \preceq x_{1} \preceq \cdots \preceq x_{k}$.

We suppose that:

(i) $d(x, y) \leq \rho(x, y)$ for all $x, y \in X$ with $x \preceq y$;

(i i ) $(X, d)$ is a complete metric space;

(i i i ) $f:\left(X^{k}, d\right) \rightarrow(X, d)$ is continuous and nondecreasing with respect to " $\preceq$ ";

Then:

(a) $f$ has a unique fixed point $x^{*}, F_{f}=x^{*}, f\left(x^{*}, x^{*}, \ldots, x^{*}\right)=x^{*}$;

(b) the sequence $\left\{x_{n}\right\}_{n \geq 0}$ with $x_{0}, \ldots, x_{k-1} \in X$ and

$$
x_{n+1}=f\left(x_{n}, x_{n-1}, \ldots, x_{n-k+1}\right), n \geq k-1,
$$

converges to $x^{*}$;

(c) the sequence $\left\{y_{n}\right\}_{n \geq 0}$,

$$
y_{n+1}=f\left(y_{n}, y_{n}, \ldots, y_{n}\right)=F\left(y_{n}\right),
$$

for all $n \geq 0, y_{0} \in X$ such that $y_{0} \preceq x^{*}$, converges to $x^{*}$ as well;

(d) the following estimate holds

$$
\rho\left(x_{n+1}, x^{*}\right) \leq C \cdot \theta^{n}, n \geq 0,
$$

where $C$ is a positive constant and $\theta \in(0,1)$.

Proof of this theorem follows from a similar process as used in the proof of theorem 4.

\section{REFERENCES}

[1] S. Banach, "Sur les óperations dans les ensembles abstraits et leur application aux équations intégrales," Fund. Math, vol. 3, pp. 133-181, 1922.

[2] R. Kannan, "Some results on fixed points," Bull. Calcutta Math. Soc, vol. 10, pp. 71-76, 1968.

[3] M. G. Maia, "Un'osservazione sulle contrazioni metriche," Rend. Sem. Mat. Univ. Padova, vol. 40, pp. 139-143, 1968.

[4] S. B. Prešić, "Sur une classe d'inéquations aux différences finies et sur la convergence de certaines suites," Publ. Inst. Math. (Beograd) (N.S.), vol. 5, no. 19, pp. 75-78, 1965.

[5] M. Păcurar, Iterative methods for fixed point approximation. Risoprint, 2009. 
[6] M. Păcurar, "A multi-step iterative method for approximating fixed points of prešić-kannan operators," Acta Math. Univ. Comenian. (N.S.), vol. 79, no. 1, pp. 77-88, 2010.

[7] I. A. Rus, "An abstract point of view in the nonlinear difference equations," Conf. on An., Functional Equations, App. and Convexity, Cluj-Napoca, pp. 272-276, 1999.

[8] I. A. Rus, A. Petruşel, and G. Petruşel, Fixed Point Theory. Cluj University Press, 2008.

[9] S. Shukla and S. Radenović, "Prešić-maia type theorems in ordered metric spaces," G. J. Math., vol. 2, no. 2, pp. 73-82, 2014.

Author's address

Margareta-Eliza Balazs

Technical University of Cluj-Napoca, North University Center at Baia Mare 